\title{
Novel indotricarbocyanine dyes covalently bonded to polyethylene glycol for theranostics
}

\author{
Alexander A. Lugovski ${ }^{a, *}$, Michael P. Samtsov ${ }^{b}$, Kirill N. Kaplevsky ${ }^{a}$, Dmitri Tarasau ${ }^{\mathrm{b}}$, \\ Eugene S. Voropay ${ }^{\mathrm{a}}$, Petr T. Petrov ${ }^{\mathrm{c}}$, Yuri P. Istomin ${ }^{\mathrm{d}}$ \\ a Belarussian State University, 220030 Minsk, Belarus \\ ${ }^{\mathrm{b}}$ A.N Sevchenko Institute for Applied Physical Problems of BSU, 220045 Minsk, Belarus \\ ${ }^{\mathrm{c}}$ The Institute of Bioorganic Chemistry, National Academy of Sciences, 220141 Minsk, Belarus \\ ${ }^{\mathrm{d}}$ N.N Alexandrovs National Cancer Centre of Belarus, 223040 Minsk, Belarus
}

A R T I C L E I N F O

Article history:

Received 30 April 2015

Received in revised form 4 October 2015

Accepted 10 October 2015

Available online $\mathrm{xxx}$

\section{Keywords:}

Indotricarbocyanine dyes

Photodynamic therapy

HeLa cells

Photo and dark cytotoxicity

\begin{abstract}
A B S T R A C T
The synthesis methods for the indotricarbocyanine dyes covalently bonded to polyethylene glycols with varying degrees of polymerization have been developed. New indotricarbocyanine was synthesized in one step using the Mukayama reagent in polyethylene glycol with cesium fluoride as a basic catalyst. In vivo investigation of the phototherapeutic dye activity has shown selective recognition of malignant tissues, where accumulation of the dye was $4-5$ times higher than in normal tissues. The necrotic area after local photoirradiation at the effective energy fluence $180 \mathrm{~J} / \mathrm{cm}^{2}, \lambda=780 \mathrm{~nm}$ was observed to a depth of $2.5 \mathrm{~cm}$ making the synthesized dyes very promising for further pharmaceutic research.
\end{abstract}

(c) 2015 Elsevier B.V. All rights reserved.

\section{Introduction}

Polymethine dyes attract much attention because of their potential applications in medicine and biology. Series of symmetrical polymethine dyes (ICG, Cy5.5, Cy7.0, IR783, etc.) containing a variety of the bis-N-substituted indole or benzindole moieties linked by linear conjugation with and without a fused substituted ring have been extensively used as reagents for in vivo tumor imaging [1-6]. In the last few years indotricarbocyanine dyes have shown themselves as effective imaging agents incorporated into the nanoparticles for cancer theranostics. $[3,7,8]$.

At the present time the porphyrin-based photosensitizers (porphyrins, chlorines, phthalocyanines, bacteriochlorines) are generally used for photodynamic therapy (PDT). However, compared with cyanine dyes, most of the porphyrin-based photosensitizers have a lower absorption wavelength (650$700 \mathrm{~nm}$ ) that is not optimal for deep penetration into tissues. Among the cyanine dyes, indotricarbocyanine dyes exhibit longwavelength absorption in the region $700-800 \mathrm{~nm}$. It is now established that light in the near IR spectral region possesses a maximal power of penetration into the majority of biological tissues $[9,10]$. Besides, with the use of cyanine dyes, one can

\footnotetext{
* Corresponding author. Fax.: +375 172125307.

E-mail address: lugovski1111@gmail.com (A.A. Lugovski).
}

combine optical imaging of tumors and phototherapy due to their high $\left(>10^{5} \mathrm{M}^{-1} \mathrm{~cm}^{-1}\right.$ ) molar extinction coefficient (higher than that of a porphyrin-based photosensitizer) and fluorescence in the "tissue transmission window". As shown previously, indotricarbocyanine dyes with a bromide anion demonstrate the photodynamic activity under hypoxic conditions [11]. This emphasizes the fact that indotricarbocyanine-based photosensitizers are an alternative for the traditional means of cancer cell damage. Modification of indotricarbocyanine dyes by biocompatible objects should lead to the increased tumor specificity. Because of this, indotricarbocyanine dyes are suggested as suitable photosensitizers for PDT.

Previously it has been reported [11-13] that some of the synthesized indotricarbocyanine dyes covalently bonded to monosaccharides demonstrate high photodynamic activity against a wide range of tumors. However, the limitation of these dyes was their insufficient water solubility for the effective intravenous injection. To increase water solubility of the dyes, tricarbocyanine covalently bonded to polyethylene glycols with varying degrees of polymerization was synthesized. In this way new dyes have a much greater solubility in water (higher than $10 \mathrm{mg} / \mathrm{ml}$ ). Moreover, these compounds exhibit greater accumulation selectivity in tumors than in normal tissues and lower toxicity compared to the dyes modified by monosaccharides. 
2<smiles>CC1=[N+](CC(=O)O)c2ccccc2C1(C)C</smiles>

(1)

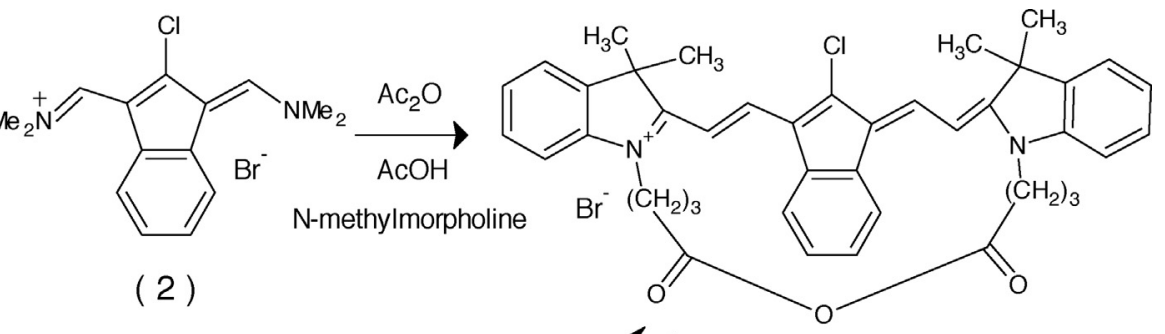

( 3 )<smiles>CN1/C(=C\C=C2\C(Cl)=C(OC(=O)OC(C)(C)C)c3ccccc32)C(C)(C)c2ccccc21</smiles>

(4)

Scheme 1. Synthesis procedure for dyes $\mathbf{3 , 4}$.

\section{Synthesis}

Synthesis of the compounds $(\mathbf{5 a}, \mathbf{5 b})$ along with their precursors is illustrated by Schemes 1 and 2. Scheme 1 demonstrates the synthesis of compound $\mathbf{3}$ obtained by the condensation reaction of indolium salt $\mathbf{1}$ with salt $\mathbf{2}$ in acetic acid, acetic anhydride in the presence of $\mathrm{N}$-methylmorpholine. Compound $\mathbf{3}$ is obtained in the anhydride form $\mathbf{3}$ and may be converted to the acid form 4 by treatment with water in the acidic medium. The existence of the anhydride form (3) is confirmed by the fact that there are no vibrations in the region $3550-3500 \mathrm{~cm}^{-1}$ of an IR spectrum.The inverse transformation (4- 3) may be realized by heating in 1,2-dichloroethane with equimolar azeotropic removal of water. It should be noted that compound $\mathbf{3}$ is much less soluble in 1,2-dichloroethane than compound $\mathbf{4}$, that can effectively purify compound 3 from nonpolar organic impurities by the inverse transformation procedure.

Scheme 2 shows the process of synthesizing the cyanine-dye modified polyethylene glycols with the average molecular weight 300 and $400 \mathrm{~g} / \mathrm{mol}$. The reaction is carried out in a single step using the Mukayama reagent (1-methyl-2-bromopyridine methyl sulfonate) in the polyethylene glycol used both as a reactant and a solvent. Cesium fluoride was used as a basic catalyst.

Subsequent isolation of the dye was carried out by the addition of ethyl acetate. Salts of inorganic acids and 1-methyl-2bromopyridine were separated by filtration after dissolving the cyanine dye in dichloroethane. The presence of a pure dye was confirmed by ${ }^{1} \mathrm{H}$ NMR and MS. Dyes $\mathbf{5 a}$ and $\mathbf{5 b}$ in mass spectra are shown as multiple peaks corresponding to dye $\mathbf{3}$ bonded to polyethylene glycols with various degrees of polymerization.

\section{Photophysical properties}

A maximal absorption wavelength of the dye $\mathbf{5 a}$ is observed at $723 \mathrm{~nm}$ in ethanol, at $733 \mathrm{~nm}$ in chloroform, and at $734 \mathrm{~nm}$ in biological structures (HeLa cells). It should be noted that the synthesized dyes have strong absorptions in the near infrared region coincident with a "phototherapeutic window" (700$900 \mathrm{~nm}$ ). Maximum of a fluorescence spectrum of the dye in ethanol is located at $\lambda=749 \mathrm{~nm}$ and in chloroform - at $\lambda=761 \mathrm{~nm}$

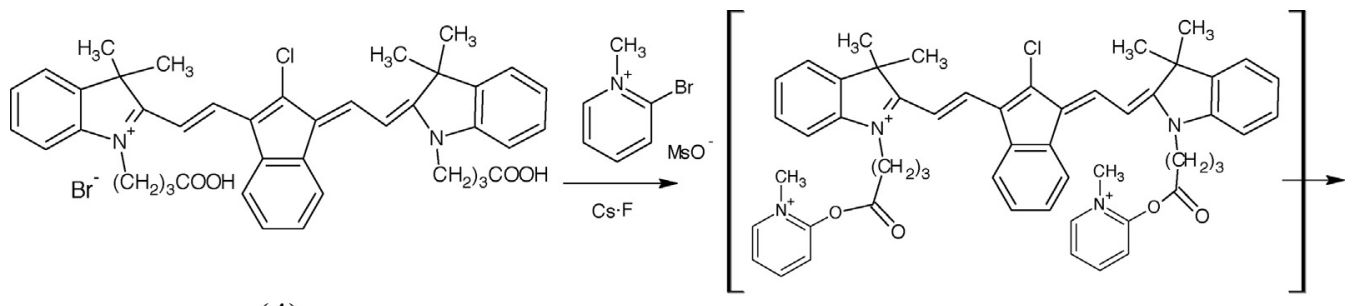

(4)<smiles>CCOCCN1C(=CC=C2C(Cl)=C(C=CC3=[N+](CCOC(=O)OCC)c4ccccc4C3(C)C)c3ccccc32)C(C)(C)c2ccccc21</smiles>

$(5 \mathrm{a}, 5 \mathrm{~b})$

Scheme 2. Synthesis procedure for compounds $\mathbf{5 a}, \mathbf{5 b}$. 


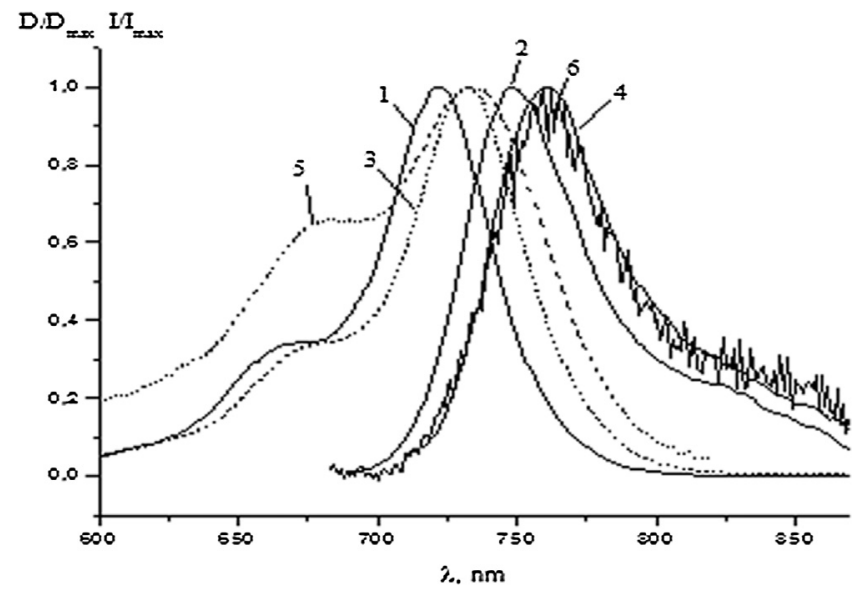

Fig. 1. Absorption (1,3,5) and fluorescence $(2,4,6)$ spectra of dye $\mathbf{5 a}$ in ethanol $(1,2)$, chloroform $(3,4)$, and in HeLa cells $(5,6)$. (For interpretation of the references to color in this figure legend, the reader is referred to the web version of this article.)

(Fig. 1). The molar decadic absorption coefficient $(\varepsilon)$ is equal to $2.3 \times 10^{5} \mathrm{M}^{-1} \mathrm{~cm}^{-1}$. The fluorescence quantum yield of the dye $\left(\varphi_{\mathrm{f}}\right)$ has similar values in ethanol and in chloroform: 0.25 and 0.26 , respectively. Close values of the fluorescence quantum yield of the dye in ethanol and in chloroform stem from several factors. It should be noted that, for cyanine dyes, the effect exerted by polarity and viscosity of the dye surrounding medium on the probabilities of radiative and radiationless transitions in the molecules is significant $[14,15]$. The importance of the abovementioned factors for the fluorescence quantum yield of the dye molecules with bulk substituents will be studied further.

In HeLa cells a maximum of absorption for the dye is observed at $\lambda=735 \mathrm{~nm}$, and the fluorescence spectrum is practically identical with the spectrum in chloroform showing a maximum at $\lambda=761 \mathrm{~nm}$ (Fig. 1). Absorption and fluorescence spectra of the dye in HeLa cells have been recorded in molecular suspension. To this end, the dye in isotonic solution was introduced into the nutrient medium over the cell monolayer and incubated for $2 \mathrm{~h}$ in thermostat at $37^{\circ} \mathrm{C}$. Then the preparation was washed off with the use of balanced Hanks salt solution and the cell monolayer was dispersed using a $0.02 \%$ Versen solution. The produced suspension ( 2 million cells per $1 \mathrm{~cm}^{3}$ ) was placed into the $1 \mathrm{~cm}$ optical cell, where it was continuously stirred, to record the spectral characteristics. The short-wavelength edge of the normalized absorption spectrum for the dye in HeLa cells is higher than that in organic solvents. Most likely, this is due to the fact that the dye in the cells is partially in the aggregated state as indicated by the increased contribution of the short-wavelength shoulder in spectra with the increased dye concentration used on incubation of the cell monolayer.

The dye sensibilization quantum yield for the generation of singlet oxygen $\left(\varphi_{\Delta}\right)$ determined by recording the luminescence of oxygen in the region $1270 \mathrm{~nm}$ equals 0.0024 in ethanol and 0.033 in chloroform. It is noteworthy that the lifetime of ${ }^{1} \mathrm{O}_{2}$ was determined during measurements with photosensitization by standards and test compounds: $12 \pm 1 \mu \mathrm{s}$ in EtOH and $248 \pm 6 \mu \mathrm{s}$ in $\mathrm{CHCl}_{3}$. The differences in the quantum yields for the generation of singlet oxygen are resultant from various polarities of the used solvents (chloroform and ethanol) and from the presence of $\mathrm{a} \mathrm{Br}$ anion in the dye molecule. In low polarity chloroform, due to the bulk substituents within the molecule, the dye is predominantly in the form of contact ion pairs. The presence of heavy atoms in the anion $(\mathrm{Br})$ even at low concentrations can enhance intersystem crossing if the cation and the anion are in close proximity (as a contact pair). In polar ethanol the dye molecules dissociate into ions and, for the concentrations used, no heavy atoms of $\mathrm{Br}$ are revealed in solution. But we bear in mind that the oxygen diffusion rate for most organic solvents at room temperature is such that the ${ }^{1} \mathrm{O}_{2}$ generation quantum efficiency for complex organic molecules is practically coincident with the yield in the triplet state $[16,17]$. Therefore, the value of $\varphi_{\Delta}$ is determined by the yield of the dye molecule in the triplet state.

The absorption and fluorescence results for $\mathbf{5 b}$ are the same as for $\mathbf{5 a}$.

The form of an absorption spectrum for the dye in water is dependent on the solution concentration. In diluted solutions with the concentration below $2 \times 10^{-7} \mathrm{M}$ the form of an absorption spectrum is similar to that in organic solvents. The band maximum is at $706 \mathrm{~nm}$, the molar absorption factor is $1.6 \times 10^{5} \mathrm{M}^{-1} \mathrm{~cm}^{-1}$. A growth of the concentration leads to broadening of the absorption band and also to lowering of the absorption factor at the band maximum. When the concentration is varying over the range $10^{-5} \div 10^{-7} \mathrm{M}$, a series of absorption spectra exhibits the isosbestic point that indicates the presence of two absorbing centers in the solution. With the concentration above $10^{-6} \mathrm{M}$, a spectrum in water reveals two marked maxima at $\lambda=658 \mathrm{~nm}$ and at $\lambda=706 \mathrm{~nm}$ (Fig. 2).

A maximum of the dye fluorescence spectrum in water is found at $\lambda=738 \mathrm{~nm}$, the fluorescence quantum yield being 0.03 for the dye concentrations $2 \times 10^{-7} \mathrm{M}$ and lower. The form and the position of a fluorescence spectrum is independent of the excitation wavelength. These results point to the tendency of the dye for aggregation and for the formation of nonfluorescent $\mathrm{H}$ dimers.

\section{Cytotoxicity studies}

\subsection{Dark toxicity of new dyes}

To study the dark toxicity of new dyes $50-200 \mu$ l of the isotonic ( $5 \%$ of glucose) dye solution was introduced into flasks with the cellular monolayer in the concentrations ranging from 2 to $800 \mu \mathrm{M}$. The flasks in the light protecting containers were incubated in thermostat at a temperature of $37^{\circ} \mathrm{C}$ for $2 \mathrm{~h}$; the preparation was washed off with a cold balanced Hanks salt solution, fresh nutrient medium was added, and the flasks were placed into thermostat again. In $24 \mathrm{~h}$ the cell monolayer was

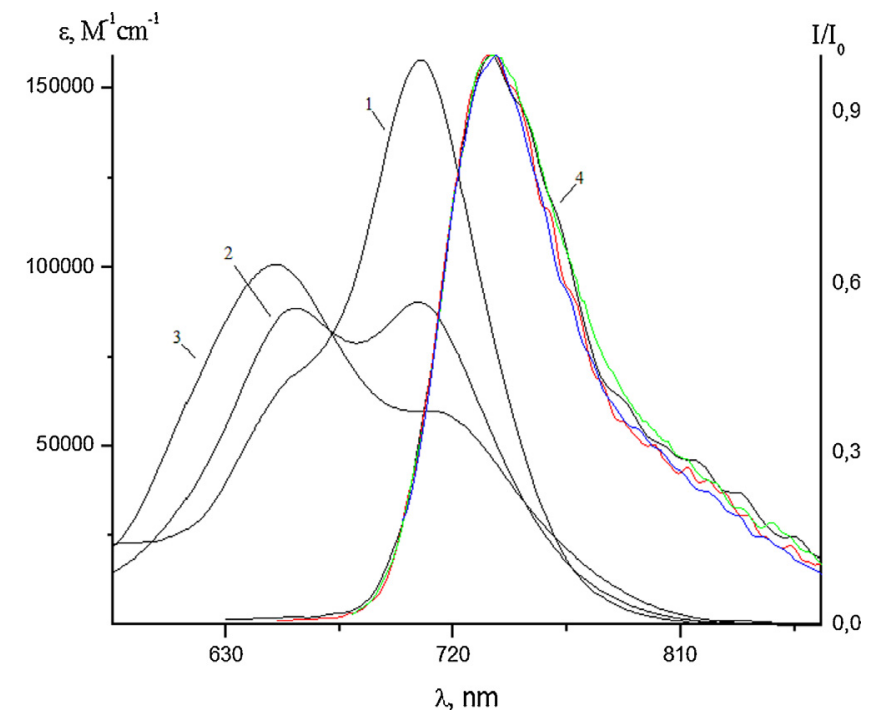

Fig. 2. Absorption spectra of dye $\mathbf{5 a}$ in water for the concentrations $1.7 \times 10^{-7} \mathrm{M}-$ (1), $1.7 \times 10^{-5} \mathrm{M}(2), 8.9 \times 10^{-4}$ (3) and fluorescence (4) on excitation at the wavelengths $620,640,670$, and $690 \mathrm{~nm}$. 


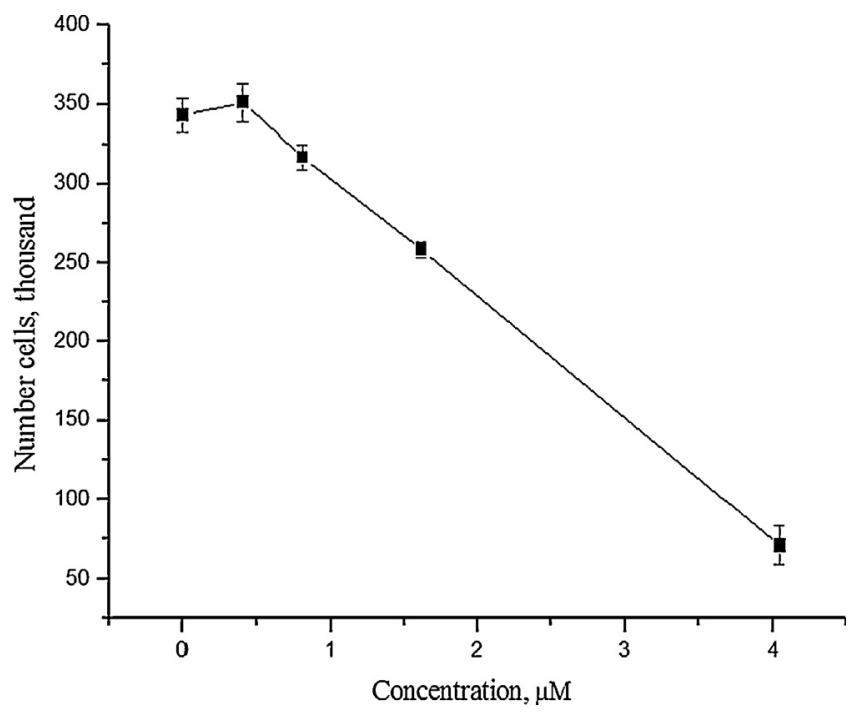

Fig. 3. Photocytotoxicity of the dye under the effect of optical radiation $(\lambda=740 \mathrm{~nm}$, fluence $10 \mathrm{~J} / \mathrm{cm}^{2}$, fluence rate $17 \mathrm{~mW} / \mathrm{cm}^{2}$ ) as a function of the concentration.

dispersed with the use of $0.02 \%$ Versen solution; $0.1 \%$ solution of Trypan blue was added to the produced suspension (1:10), and the living cells nonstained with Trypan blue were counted in a Goryaev chamber. Percentage of the survival rate of cells in experimental groups was estimated relative to the reference group. 3 cell flasks were used for every concentration.

The number of viable HeLa tumor cells after incubation for $2 \mathrm{~h}$ in the medium containing $2 \mu \mathrm{M}$ or $4 \mu \mathrm{M}$ of the preparation was not very different from the reference values. As the dye concentration in the incubation medium is growing, the cell numbers are lowering: for $8 \mu \mathrm{M}$ by $9 \%$, for $20 \mu \mathrm{M}$ by $19 \%$, for $40 \mu \mathrm{M}$ by $60 \%$, and for $80 \mu \mathrm{M}$-by $73 \%$ with respect to the reference. In this way nontoxic concentrations of the dye are below $8 \mu \mathrm{M}$.

The effective concentration of the dye leading to $50 \%$ decrease in the cell numbers relative to the reference comes to $36 \mu \mathrm{M}$.

\subsection{Phototoxicity of new dyes}

The photoactivity of the dye has been studied with the use of the monolayer culture of HeLa tumor cells. The dye in a isotonic solution was introduced into the nutrient medium in flasks and incubated for $2 \mathrm{~h}$ in thermostat at $37^{\circ} \mathrm{C}$. Then the preparation was washed off with the use of balanced Hanks salt solution, a fresh nutrient medium was added to be subjected to $740 \mathrm{~nm}$ radiation of a Lotis semiconductor laser (Minsk) with the dose $10 \mathrm{~J} / \mathrm{cm}^{2}$ and the fluence rate $17 \mathrm{~mW} / \mathrm{cm}^{2}$. Living cells were counted in $24 \mathrm{~h}$ after irradiation performed in accordance with the technique described in section Dark toxicity.

Without the use of a photosensitizer, laser irradiation has no effect on the quantities of cells in HeLa culture. At the same time, optical radiation after incubation with the dye has lead to a significant deceleration of the HeLa culture growth that was greatly dependent on the dye concentration (Fig. 3). The effective concentration of the preparation leading to a decrease in the cell numbers by $50 \%$ with respect to the reference value is $2.7 \mu \mathrm{M}$.

\section{In vivo antitumor activity}

In vivo investigations of the toxicity were performed on rats (Wistar strains) using intravenous injection of the dye. It has been found that $50 \%$ mortality of the animals was observed for the following concentrations of compound 5a: 1646.6 $(1528.6 \div 1770.3) \mathrm{mg} / \mathrm{kg}$ for male Wistar rats, 1264.2 $(963.6 \div 1445.6) \mathrm{mg} / \mathrm{kg}$ for female Wistar rats.

The antitumor activity was estimated for white rats of no breed (100-150g of bodyweight) with subcutaneously transplanted tumors (sarcoma M-1 and liver cancer RS-1). The tricarbocyanine dye was injected intravenously at a dose of $4-5 \mathrm{mg} / \mathrm{kg}$ via a lateral tail vein. The kinetics of the dye accumulation was studied by the fluorescence detection in vivo. The synthesized tricarbocyanine showed selective recognition for malignant tissues, where its accumulation was $4-5$ times higher than in normal tissues. A wide absorption band of the dye can be used in the process of the PDT treatment at the wavelengths $660-780 \mathrm{~nm}$. As found previously [18], the highest efficiency of the tumor tissue damage was attained when using the radiation wavelength $780 \mathrm{~nm}$.

Photoirradiation of tumors with the synthesized dye was carried out at several wavelengths $(668,740$, and $780 \mathrm{~nm})$. The local photoirradiation of tumors with the effective energy fluence $160-180 \mathrm{~J} / \mathrm{cm}^{2}$ in $2 \mathrm{~h}$ after the dye injection into the rats resulted in the unstained (Evans's blue) necrotic area formed in a tumor tissue from the side of the light irradiation source. The necrotic area was observed down to a depth of $2.5 \mathrm{~cm}$ (Table 1 ).

Furthermore, it has been found that the synthesized dye molecules have a small quantum yield of the singlet oxygen generation. Based on the previous works [11,12,19], it has been concluded that the photoactivity mechanism of this class of compounds is beyond the scope of the scheme according to which the tumor cell damage is solely due to the formation of singlet oxygen. Proceeding from analysis of the irreversible phototransformation regularity of the molecules in deoxygenated and oxygenated solutions and from the femtosecond spectroscopy data, it has been established that the free radicals, which may be responsible for the cancer cell damage, are formed due to the ultrafast charge transfer between cations and anions of the dye $[20,21]$.

\section{Experimental}

\subsection{General methods and materials}

${ }^{1} \mathrm{H}$ NMR spectra were recorded by a Bruker DRX instrument at $500 \mathrm{MHz}$. The chemical shifts are reported in ppm. Mass spectra were obtained with the help of an Agilient 1200 Rapid Resolution LC and an Agilient 6410 Triple Quad mass-detector. Infrared spectra were measured by a Vertex 70 Bruker spectrometer. UVvis-NIR spectra were recorded using Varian Cary 500. Fluorescence spectra were recorded using a Fluorolog spectrofluorometer. The fluorescence quantum yields of the dye were calculated relative to the standard from their respective average fluorescence spectrum

Table 1

Phototherapeutic effect of dye 5a in the case of sarcoma M-1 and liver cancer RS- 1 .

\begin{tabular}{|c|c|c|c|c|c|}
\hline Strain & $\begin{array}{l}\text { Dye concent-ration } \\
\mathrm{mg} / \mathrm{kg}\end{array}$ & $\begin{array}{l}\text { Photoirra-diation wavelength, } \\
\mathrm{nm}\end{array}$ & Fluence rate, $\mathrm{W} / \mathrm{cm}^{2}$ & $\begin{array}{l}\text { Effective energy fluence, } \\
\mathrm{J} / \mathrm{cm}^{2}\end{array}$ & Average depth of necrosis, mm \\
\hline Sa M-1 & 4 & 780 & 0.45 & 180 & $25 \pm 2$ \\
\hline Sa M-1 & 4 & 740 & 0.2 & 180 & $18 \pm 2$ \\
\hline Sa $M-1$ & 4 & 668 & 0.6 & 180 & $12 \pm 2$ \\
\hline RS-1 & 5 & 740 & 0.25 & 160 & $19 \pm 2$ \\
\hline RS-1 & 5 & 668 & 0.7 & 160 & $13 \pm 2$ \\
\hline
\end{tabular}


areas and the published quantum yield of the standard, which in this case was HITC $\left(1,3,3,1^{\prime}, 3^{\prime}, 3^{\prime}\right.$,-hexamethyl-2,2'-indotricarbocyanine perchlorate) dye $\left(\varphi_{\mathrm{f}}=0.28\right.$ in ethanol $)[22,23]$. The 900 geometry of the quantum yield measurements was used; the optical density of samples at maximal absorption was below 0.1 .

\subsection{Experimental procedure}

6.2.1. Synthesis of 2-\{7-[1-(3-carboxypropyl)-3,3-dimethyl-2(1H)indolynilidene -4-chloro-3,5-(o-phenylene)-1,3,5-heptatrien-1-yl\}1-(3- carboxypropyl)- 3,3-dimethylindolium bromide (3)

$0.105 \mathrm{~mol}$ (34 g) 1-(3-carboxypropyl)-3-ethyl-2,3-dimethyl$3 \mathrm{H}$-indolium bromide (1) and $60 \mathrm{ml}$ of acetic anhydride were dissolved in $200 \mathrm{ml}$ of acetic acid and stirred at temperatures 60$70^{\circ} \mathrm{C}$ for $15 \mathrm{~min}$. The reaction mixture was then cooled to a room temperature and $0.05 \mathrm{~mol}(16 \mathrm{~g})\{(1 \mathrm{E})-2$-chloro-1-[(dimethylamino) methylidene]-1H-inden-3-yl\}-N,N-dimethylmethaniminium bromide (2) was added. Next the reaction mixture was stirred at temperature $70^{\circ} \mathrm{C}$ for $15 \mathrm{~min}$ and $0.05 \mathrm{~mol} \mathrm{~N}$-methylmorpholine $(5 \mathrm{ml})$ was added. Thereafter the resulting mixture was heated under reflux for $10 \mathrm{~min}$, cooled to room temperature, and finally poured into the solution of $20 \mathrm{~g}$ salt in $1000 \mathrm{ml}$ water to be left at room temperature overnight. The cooled mixture was filtered; the resultant precipitate was washed with water and dried. The synthesized dye was dissolved in $200 \mathrm{ml}$ of 1,2dichloroethane and was refluxed for $15 \mathrm{~min}$. The precipitate was filtered and dried. The dye yield was $29.7 \mathrm{~g}$ (Fig. 1).

M.p. $226^{\circ} \mathrm{C}$ (destr.), yield $80 \%$, green metallic powder. Analytical data for dye 3. IR (vaseline): $1829 \mathrm{~cm}^{-1}, 1760 \mathrm{~cm}^{-1}(\mathrm{C}=\mathrm{O})$, $1620 \mathrm{~cm}^{-1}, 1660 \mathrm{~cm}^{-1}$ ( $\mathrm{C}=\mathrm{C}$ trans). ${ }^{1} \mathrm{H} \mathrm{NMR}\left(\mathrm{CDO}-\mathrm{N}\left(\mathrm{CD}_{3}\right)_{2}\right.$, $500 \mathrm{MHz}) \delta: 1,85(\mathrm{~s}, 12 \mathrm{H}, 3-\mathrm{Me}), 1.96\left(\mathrm{~m}, 4 \mathrm{H}, 1-\mathrm{C}^{2} \mathrm{H}_{2}\right), 2.29$ (t, $4 \mathrm{H}, 1-\mathrm{C}^{3} \mathrm{H}_{2} ; J=5 \mathrm{~Hz}$ ), 4.28 (t, $\left.4 \mathrm{H}, 1-\mathrm{C}^{1} \mathrm{H}_{2} ; J=5 \mathrm{~Hz}\right), 8.47,7.34$ $(\mathrm{d}, 4 \mathrm{H},-\mathrm{CH}=; J=16 \mathrm{~Hz}) ; 7.49,7.61,7.82,8.22,8.27(\mathrm{~m}, 12 \mathrm{H}$, arom.-H). ${ }^{13} \mathrm{C}$ NMR $\left(\mathrm{CD}_{3} \mathrm{CN}, 500 \mathrm{MHz}\right): 178.06,172.85,144.63$, $142.17,141.93,141.63,134.05,128.96,126.60,125.57,123.73,122.56$, $121.65,112.36,102.41,50.24,44.24,30.28,27.44,22.18$. HRMS: $\mathrm{m} / z$ calcd $661.282\left[\mathrm{M}^{+}\right]$, found $661.20\left[\mathrm{M}^{+}\right]$.

6.2.2. Synthesis of polyethylene glycole diester of 2-\{7-[1-(3carboxypropyl)-3,3-dimethyl-2(1H)-indolynilidene]-4-chloro-3,5(o-phenylene)-1,3,5-heptatrien-1-yl\}-1-(3-carboxypropyl)- 3,3dimethylindolium bromide (5a)

Cesium fluoride $(0.030 \mathrm{~mol})$ was dissolved in $33 \mathrm{~g}$ of anhydrous polyethylene glycole with the average molecular weight $300 \mathrm{~g} /$ mol. $0.006 \mathrm{~mol}$ tricarbocyanine dye (3) and $0.015 \mathrm{~mol} 2$-bromopyridine methane sulfonate were added and stirred at temperature $40^{\circ} \mathrm{C}$. The reaction mixture was then refluxed for $9 \mathrm{~h}$. After cooling, the flask content was mixed with $100 \mathrm{ml}$ of ethyl acetate for the precipitation of diester of the cyanine dye. The precipitate was filtered and then dissolved in 1,2-dichloroethane. The reaction mixture was subjected to column chromatography on microcrystalline cellulose $(20 \pm 160 \mu \mathrm{m})$ using ethyl acetate \pm aceton $(1: 1 / \mathrm{v}$ : $v)$ as an eluent. Then the isolated cyanine dye was precipitated by diethyl ether and twice reprecipitated from methyl ethyl ketone by diethyl ether. The yield was 67\% (Fig. 2), brown oil.

Dye $\mathbf{5 b}$ was obtained using a similar procedure.
Analytical data for compounds $\mathbf{5 a}(\mathbf{5 b}){ }^{1} \mathrm{H} \mathrm{NMR}\left(\mathrm{CDO}-\mathrm{N}\left(\mathrm{CD}_{3}\right)_{2}\right.$, $500 \mathrm{MHz}$ ): 1.85 (s, $12 \mathrm{H}$ in 3-Me), $1.96\left(\mathrm{~m}, 4 \mathrm{H}, 1-\mathrm{C}^{2} \mathrm{H}_{2}\right), 2.29(\mathrm{~m}$, $\left.4 \mathrm{H}, 1-\mathrm{C}^{3} \mathrm{H}_{2} ; J=5 \mathrm{~Hz}\right), 3.6-3.7$ м $\left(\mathrm{CH}_{2}-\mathrm{PEG}\right), 4.28(\mathrm{~m}, 4 \mathrm{H}$, $\left.1-\mathrm{C}^{1} \mathrm{H}_{2} ; J=5 \mathrm{~Hz}\right), 8.47,7.34$ (d, $\left.4 \mathrm{H},-\mathrm{CH}=; J=16 \mathrm{~Hz}\right) ; 7.49,7.61$, 7.82, 8.22, 8.27 (m, 12H, arom.-H). ${ }^{13} \mathrm{C}$ NMR $\left(\mathrm{CD}_{3} \mathrm{CN}, 500 \mathrm{MHz}\right)$ : $176.95,172.85,144.63,142.17,141.93,141.63,134.05,128.96,126.60$, 125.57, 123.73, 122.56, 121.65, 112.36, 102.41, 72.36, 70.11, 68.69, 63.9, 50.24, 44.24, 30.28, 27.44, 22.18. HRMS (5a): $\mathrm{m} / z$ calcd $1145.571 ; 1189.597 ; 1233.623\left[\mathrm{M}^{+}\right]$, found $1145.4 ; 1189.4 ; 1233.4$ [ $\left.\mathrm{M}^{+}\right]$; HRMS (5b): $\mathrm{m} / z$ calcd: $1409.728 ; 1453.754 ; 1497.780\left[\mathrm{M}^{+}\right]$, found: $1409.6 ; 1453.6 ; 1497.6\left[\mathrm{M}^{+}\right]$

Absorption and fluorescence data in Table 2.

\subsection{Quantum yields of the singlet oxygen formation}

Using a relative method, the quantum yield of ${ }^{1} \mathrm{O}_{2}$ formation $\left(\varphi_{\Delta}\right)$ was determined by recording of the decay kinetics for the singlet oxygen phosphorescence in the spectral region $1270 \mathrm{~nm}$. Luminescence of ${ }^{1} \mathrm{O}_{2}$ was recorded using an apparatus fabricated at the Laboratory of Molecular Photonics, Institute of Physics, NASB [24]. The dyes were excited using radiation from a semiconductor laser $(\lambda=667 \mathrm{~nm})$. To obtain correct values of $\varphi_{\Delta}$, owing to the use of a relative method, the conditions for observation of the linear dependence between the luminescence signal of singlet oxygen and the energy of excitation radiation have been ensured.

The standard was $1,3,3 ; 1^{\prime}, 3^{\prime}, 3^{\prime}$-hexamethyl-2,2'-indotricarbocyanine (HITC) with perchlorate $\left(\mathrm{ClO}_{4}\right)$ in $\mathrm{CHCl}_{3} \varphi_{\Delta}=0.005 \pm 0.001$ and in EtOH $\varphi_{\Delta} \pm 0.006 \pm 0.001$ [25]. It is noteworthy that the ${ }^{1} \mathrm{O}_{2}$ lifetime was determined during measurements with photosensitization by standards and test compounds: $12 \pm 1 \mu \mathrm{s}$ in EtOH and $248 \pm 6 \mu \mathrm{s}$ in $\mathrm{CHCl}_{3}$. The standard having a low value of $\varphi_{\Delta}$ was used in an effort to provide high measuring accuracy of this parameter as the standard and the compounds under study indotricarbocyanine dyes - exhibit similar absorption spectra making it possible to smooth the optical density of a sample and of the standard at the excitation wavelength $667 \mathrm{~nm}$; besides, close values of their singlet oxygen generation efficiency in both cases have resulted in the comparable recorded signals which were within the linearity range of the recording devices used.

\subsection{HeLa Cell culture}

The culture of HeLa cells was grown in the Eagle nutrient medium (DMEM) with the addition of $10 \%$ fetal blood serum of a cow and $50 \mu \mathrm{g} / \mathrm{ml}$ of gentamicin at $37^{\circ} \mathrm{C}$. The experimental cell culture was seeded into flasks: 100 thousand cells in $2 \mathrm{ml}$ of the nutrient medium. In 3 days after seeding, at the exponential stage of the cell culture growth, $50-200 \mu$ l of the isotonic dye solution with $5 \%$ of glucose were added into the flasks with the cellular monolayer. The light-protected flasks were incubated in a thermostat at $37^{\circ} \mathrm{C}$ for $2 \mathrm{~h}$; the preparation was washed off with a cold balanced Hanks salt solution solution, a fresh nutrient medium was added to continue the experimental studies. In $24 \mathrm{~h}$ the cellular monolayer was dispersed using a $0.02 \%$ Versen solution. A $0.1 \%$ solution of trypan blue was added into the produced suspension (1:10); living (nonstained with trypan blue) cells were counted in a Goryaev chamber. Percentage of the cell

Table 2

Photophysical properties of dye $\mathbf{5 a}$

\begin{tabular}{|c|c|c|c|c|c|c|c|c|c|}
\hline Solvent & $\lambda_{\mathrm{abs}}^{\max }, \mathrm{nm}$ & $\lambda_{\mathrm{f}}^{\max }, \mathrm{nm}$ & $\Delta \lambda_{\text {abs }}^{1 / 2}, \mathrm{~nm}$ & $\Delta \lambda_{\mathrm{f}}^{1 / 2}, \mathrm{~nm}$ & $\begin{array}{l}\varepsilon \times 10^{5} \\
\mathrm{M}^{-1} \mathrm{~cm}^{-1}\end{array}$ & $\begin{array}{l}\varphi_{\mathrm{f}} \\
\left(20^{\circ} \mathrm{C}\right)\end{array}$ & $\begin{array}{l}\tau, \\
\text { ns }\left(20^{\circ} \mathrm{C}\right)\end{array}$ & $\chi_{\tau}^{2}$ & $\varphi_{\Delta}$ \\
\hline Ethanol & 723 & 749 & 47 & 51 & 2.3 & 0.25 & 1.2 & 1.32 & 0.0024 \\
\hline Chloroform & 733 & 761 & 50 & 56 & 2.3 & 0.26 & 1.4 & 1.33 & 0.033 \\
\hline Water & 706 & 738 & $>68$ & 59 & 1.6 & 0.03 & - & - & - \\
\hline
\end{tabular}


survival rate in experimental groups was estimated with respect to the reference value. 3 flasks with cells were used for every concentration of the preparation.

\subsection{In vivo antitumor activity}

All manipulations were performed with the animals brought into the neuroleptanalgesia state with the use of a solution of droperidol and fentanyl 2:1, (0.2 ml/100 $\mathrm{g}$ of mass, intramuscular). The dye was dissolved in a solution (5\% glucose) at the concentration $800 \mu \mathrm{M}$ and introduced via the tail vein.

To estimate the tumor necrosis depth in $24 \mathrm{~h}$ after the photodynamic therapy procedure, to the rats a $0.6 \%$ solution of Evans blue was introduced ( $1 \mathrm{ml} / 100 \mathrm{~g}$ of the animal mass). Then in $2 \mathrm{~h}$ the experimental procedure was finished for the animals by the conventional methods of euthanasia (chloroform), the tumors were excised, fixed in a $10 \%$ formalin solution for $2 \mathrm{~h}$, and frozen. Next the histotopographic sections of tumors were made $(2.0 \mathrm{~mm}$ thick over the tumor diameter) with subsequent recording of their images using a camera.

Laser device (manufacturer Unitary Enterprise "STC "LEMT" of the BelOMO") with wavelength $667 \mathrm{~nm}$ (up to $2 \mathrm{~W}$ radiated power) and LOTIS TII semiconductor laser with wavelength $740 \mathrm{~nm}(1 \mathrm{~W})$ were used for photodynamic therapy. LED-based theranostic complex was designed at Institute for Applied Physical Problems (Minsk, Belarus) and used both for diagnostics and photodynamic therapy [26]. Light-emitting diode of the complex (L780-66-60, Total Radiated Power $1 \mathrm{~W}$ ) allows to create on the surface of tumor fluence rate up to $0.45 \mathrm{~W} / \mathrm{cm}^{2}$ with wavelength $780 \mathrm{~nm}$.

\section{Conclusion}

This paper presents the possibility for a two-step synthesis of the indotricarbocyanine dyes covalently bonded to polyethylene glycols with varying degrees of polymerization. This modification leads to the increased water solubility and dye accumulation selectivity in tumors compared with the normal tissues. It should be noted that the cyanine dyes with polyethylene glycol having the average molecular mass $300 \mathrm{~g} / \mathrm{mol}$ may be used to produce a water soluble drug for intravenous injection. The synthesized compounds have high photodynamic activity to different types of malignant tissues, mainly owing to their lower absorptivity by the normal cells and very low toxicity. Maximum phototherapeutic activity was observed on light exposure at a wavelength of $780 \mathrm{~nm}$.

\section{Acknowledgement}

The authors are grateful to A. S. Stasheuski for his help in estimation of the quantum efficiency for singlet oxygen.

\section{References}

[1] A. Yuan, J. Wu, X. Tang, L. Zhao, F. Xu, Y. Hu, Application of near-infrared dyes for tumor imaging, photothermal, and photodynamic therapies, J. Pharm. Sci. 102 (1) (2013) 6-28.

[2] Ravindra K. Pandey, Nadine James, Yihui Chen, Mahabeer P. Dobhal, Cyanine dye-based compounds for tumor imaging with and without photodynamic therapy, Top. Heterocycl. Chem 14 (2008) 41-74.

[3] Xiaomin Yi, Fuli Wang, Weijun Qin, Xiaojian Yang, Jianlin Yuan, Near-infrared fluorescent probes in cancer imaging and therapy: an emerging field, Int. J. Nanomed. 10 (9) (2014) 1347-1365.
[4] A. Okamoto, ECHO probes: a concept of fluorescence control for practical nucleic acid sensing, Chem. Soc. Rev. 40 (12) (2011) 5815-5828.

[5] M. Levitus, S. Ranjit, Cyanine dyes in biophysical research: the photophysics of polymethine fluorescent dyes in biomolecular environments, Q. Rev. Biophys. 44 (1) (2011) 123-151.

[6] R. Oseroff, G. Ara, D. Ohuoha, J. Aprille, J.C. Bommer, M.L. Yarmush, J. Foley, L. Cincotta, Strategies for selective cancer photochemotherapy: antibodytargeted and selective carcinoma cell photolysis, Photochem. Photobiol. 46 (1) (1987) 83-96.

[7] M. Ma, Y. Hao, N. Liu, Z. Yin, L. Wang, X. Liang, X. Zhang, A novel lipid-based nanomicelle of docetaxel: evaluation of antitumor activity and biodistribution, Int. J. Nanomed. 7 (2012) 3389-3398.

[8] S. Zonghai, D. heng, H. ehong, M. u, X. iaomiao, M. ue, H. eng, P. e, G. ing, L. ong, C. intao, ai, Indocyanine Green Nanoparticles for Theranostic Applications, Nano Micro Lett. 5 (3) (2013) 145-150.

[9] S.J. Matcher, C.E. Elwell, C.E. Cooper, M. Cope, D.T. Delpy, Performance comparison of several published tissue near-infrared spectroscopy algorithms, Anal. Biochem. 227 (1) (1995) 54-68.

[10] S.J. Matcher, M. Cope, D.T. Delpy, Use of the water absorption spectrum to quantify tissue chromophore concentration changes in near-absorption spectroscopy, Phys. Med. Biol. 39 (1) (1994) 177-196.

[11] Y.P. Istomin, E.N. Alexandrova, E.A. Zhavrid, E.S. Voropay, M.P. Samtsov, K.N. Kaplevsky, A.P. Lugovsky, A.A. Lugovsky, The effect of hypoxia on photocytotoxicity of TICS tricarbocyanine dye in vitro, Exp. Oncol. 28 (1)(2006) 80-82.

[12] Y.P. Istomin, E.N. Alexandrova, V.N. Chalov, E.A. Zhavrid, E.S. Voropay, M.P. Samtsov, A.P. Lugovsky, A.A. Lugovsky, I.S. Mikhalovsky, Uptake and phototoxicity of tricarbocyanine indolenine dye covalently bound with glucose (TICS) under acidification of tumor cells environment, Exp. Oncol. 26 (3) (2004) 226-231.

[13] A. Lugovski yr, M. Samtsov, E. Voropay, A. Lugovski, K. Kaplevsky, Synthesis of tricarbocyanine dyes modified by monosaccharides - new photosensitizers for photodynamic therapy, Vestnik BSU (2012) .

[14] S.A. Soper, Q.L. Mattingly, Steady-state and picosecond laser fluorescence studies of non radiative pathways in tricarbocyanine dyes: implications to the design of near-IR fluorochromes with high fluorescence intensities, J. Am. Chem. Soc. 116 (1994) 3744-3752.

[15] M.Y. Berezin, H. Lee, W.J. Akers, S. Achilefu, Near infrared dyes as lifetime solvatochromic probes for micropolarity measurements of biological systems, Biophys. J. 93 (8) (2007) 2892-2899.

[16] A.U. Khan, Singlet molecular oxygen: a new kind of oxygen, J. Phys. Chem. 80 (1976) 2219-2227.

[17] B.M. Dzhagarov, G.P. Gurinovich, V.E. Novichenkov, K.I. Salokhiddinov, A.M. Shul'ga, V.A. Ganzha, Mechanism of quenching of triplet-states of chlorophyll and related-compounds by molecular-oxygen, Khim. Fiz. 6 (8) (1987) 919-928.

[18] M.P. Samtsov, E.S. Voropay, K.N. Kaplevsky, D.G. Melnikau, L.S. Lyashenko, Yu. P. Istomin, Influence of photon energy on the efficiency of photochemotherapy, J. Appl. Spectrosc. 4 (2009) 547-553.

[19] E. Delaey, F. van Laar, D. De Vos, A. Kamuhabwa, P. Jacobs, P. de Witte, A comparative study of the photosensitizing characteristics of some cyanine dyes, J. Photochem. Photobiol. B 55 (1) (2000) 27-36.

[20] M.P. Samtsov, S.A. Tikhomirov, O.V. Buganov, K.N. Kaplevsky, D.G. Melnikov, L. S. Lyashenko, Fast photoprocesses in a symmetric indotricarbocyanine dye (HITC) in solutions, J. Appl. Spectrosc. 6 (2009) 783-790.

[21] M.P. Samtsov, S.A. Tikhomirov, L.S. Lyashenka, D.S. Tarasau, O.V. Buganov, V.A. Galievsky, A.S. Stasheuski, E.S. Voropay, Photophysical and photochemical properties of HITC indotricarbocyanine dye molecules in solutions, J. Appl. Spectrosc. 80 (2) (2013) 170-175.

[22] J.X. Duggan, J. DiCesare, J.F. Williams, Investigations on the use of laser dyes as quantum counters for obtaining corrected fluorescence spectra in the near infrared, in: D. Eastwood (Ed.), In New Directions in Molecular Luminescence, E. ASTM, 1983, pp. 112-126 STP822.

[23] L.F. Vieira Ferreira, S.M.B. Costa, Fluorescence quantum yield evaluation of strongly absorbing dye solutions as a function of the dye concentration, J. Lumin. 48-49 (1991) 395-399.

[24] A.S. Stashevskii, V.A. Galievskii, B.M. Dzhagarov, High-sensitivity laser fluorometer for near-infrared and visible range, Prib. Metody Izmer. (2011) .

[25] M.P. Samtsov, D.S. Tarasau, A.S. Stasheuski, K.N. Kaplevsky, E.S. Voropay, Concentration increase of the singlet-oxygen generation quantum yield by an indotricarbocyanine dye, J. Appl. Spectrosc. 81 (2) (2014) 221-241.

[26] F. A. Ermalitskiy, A.E. Rad'ko, K.N. Kaplevsky, K.A. Shevchenko, Spectrometric complex with powerful LED for photochemotherapy, in: I.S. Manak (Ed.), Laser and optical-electronic equipment, 11, Publ. of Akad of publ. admin., Minsk, Belarus, 2008, pp. 260-269 (Russia). 